\title{
Erratum to: Enantioseparation of flinderoles and borreverines by HPLC on Chirobiotic V and V2 stationary phases and by $\mathrm{CE}$ using cyclodextrin selectors
}

\author{
Jonathan P. Smuts • Yun-Cheol Na • \\ Ravikrishna Vallakati • Adam Přibylka • \\ Jeremy A. May • Daniel W. Armstrong
}

Received: 26 November 2013 / Accepted: 6 December 2013 / Published online: 10 January 2014

(C) Springer-Verlag Berlin Heidelberg 2014

Erratum to: Analytical and Bioanalytical Chemistry

DOI 10.1007/s00216-013-7335-x

Regrettably there was an error in Fig. 2 where the structures of flinderole $\mathrm{B}$ and $\mathrm{C}$ have been drawn with the stereogenic methyl group adjacent to the stereogenic isoprenyl group. The correct representation of Fig. 2 is shown below as may also be found by comparing with Fig. 1 of our publication. The conclusion drawn from the figure in the publication, i.e. "in the anti configuration both faces of the flinderole are blocked for $\pi-\pi$ and hydrogen bonding interactions whereas in the syn configuration one face is more accessible", remains unchanged.

The online version of the original article can be found at http://dx.doi.org/ 10.1007/s00216-013-7335-x.

J. P. Smuts $\cdot$ D. W. Armstrong $(\bowtie)$

Department of Chemistry and Biochemistry, University of Texas at

Arlington, Arlington, TX 76019, USA

e-mail: sec4dwa@uta.edu

Y.-C. Na

Seoul Center, Korea Basic Science Institute, 136701 Seoul,

South Korea

R. Vallakati · J. A. May

Department of Chemistry, University of Houston, 136 Fleming

Building, Houston, TX 77204-5003, USA

A. Přibylka

Regional Centre of Advanced Technologies and Materials,

Department of Analytical Chemistry, Palacký University,

17. Listopadu 12, 77146 Olomouc, Czech Republic 
Flinderole C: anti arrangement

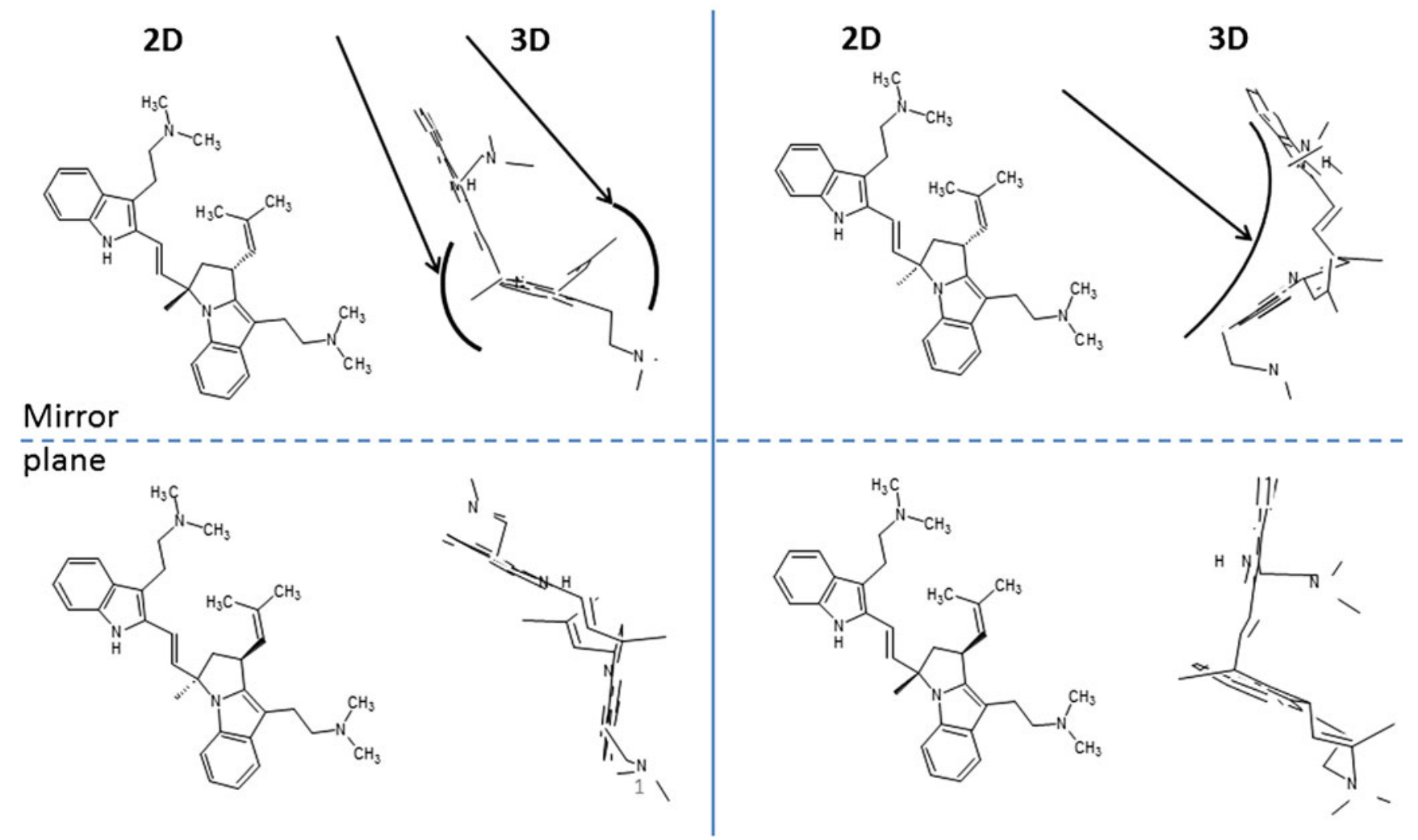

Fig. 2 A comparison of the two- and three-dimensional representations of flinderole $\mathrm{B}$ and $\mathrm{C}$ and the impact of the syn versus anti configuration of the methyl and isoprenyl groups on potential chiral recognition. Three-dimensional optimizations were conducted with ACD Chemsketch freeware 